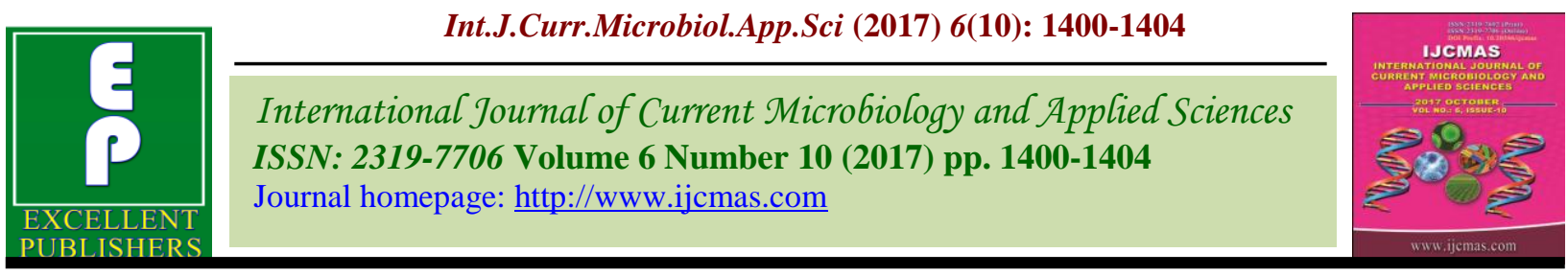

Case Study

https://doi.org/10.20546/ijcmas.2017.610.165

\title{
Theileriosis in a Calf: A Case Study
}

\author{
Sheikh Tajamul Islam*, Rouf Rashid Dar, Amir Amin Sheikh, Pooja Dogra, \\ Rohini Gupta, Priti Patel, Mohd Younis Ganaie and Jaan Mohammad Wani
}

\author{
Department of Veterinary Medicine, International Institute of Veterinary \\ Education and Research (IIVER), Rohtak Haryana-124001, India \\ *Corresponding author
}

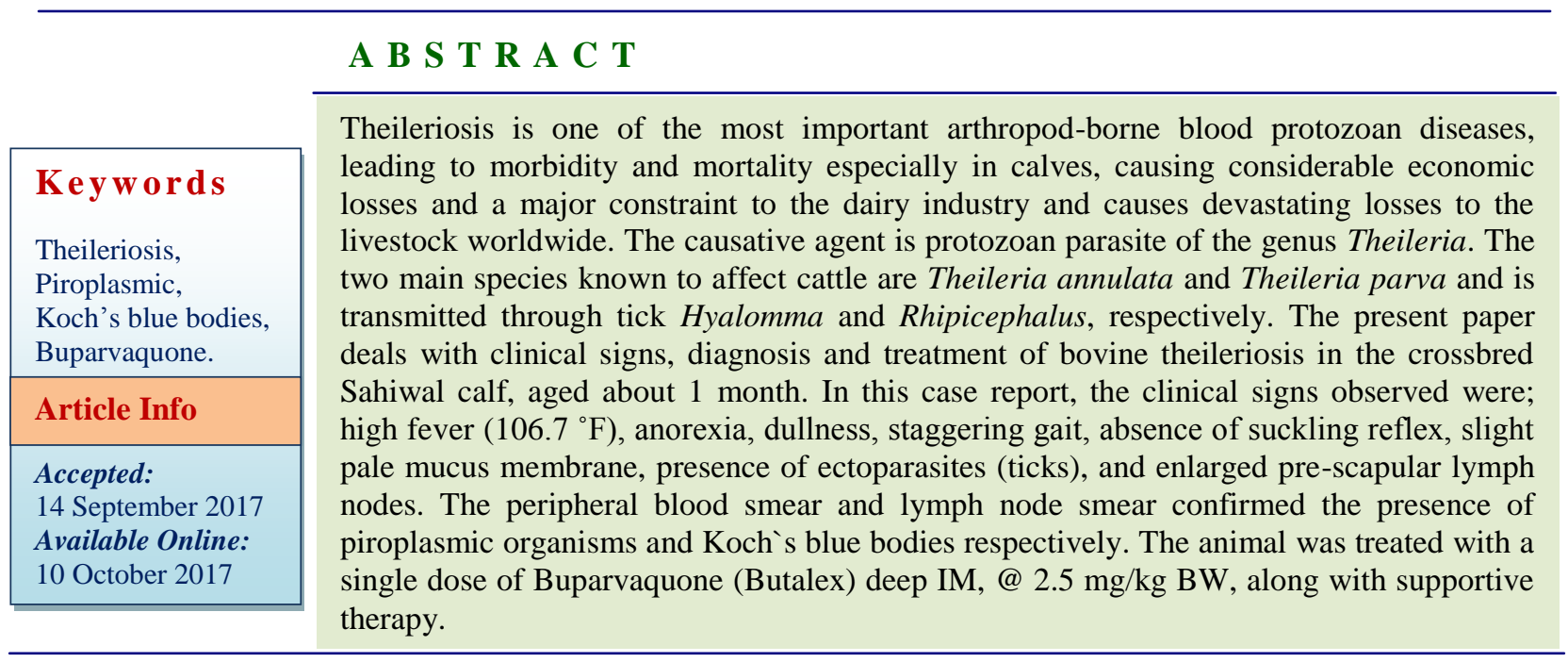

\section{Introduction}

Theileriosis is arthropod transmitted blood protozoan diseases and is economically important vector-borne diseases of tropical and subtropical parts of the world including Ethiopia (Sitotaw et al., 2014). The Theileria species infect a wide range of both domestic and wild animals and are transmitted by ixodid ticks of the genera Amblyomma, Haemaphysalis, Hyalomma and Rhipicephalus (Mans et al., 2015). T. parva can infect cattle, African buffalo, water buffalo and waterbucks. Symptomatic infections are common only in cattle and water buffalo (Spickler, 2010). T. parva is highly virulent for European dairy cattle, however, the indigenous cattle breeds and African buffaloes in endemic areas have a natural resistance to this Theileria species (Radostits, et al., 2007). They are of great economic impact on livestock affecting 80\% of the world cattle population and causes economic loss due to morbidity and mortality (Kasozi et al., 2014). Haemoprotozoan diseases are causing devastating losses to the livestock industry and thus pose major constraints to the dairy industry throughout the world (Kohli et al., 2014; Bhatnagar et al., 2015). Theileriosis is also a tick borne protozoal disease in ruminants caused by hemoprotozoan parasites belonging to the 
genus Theileria (Demessie and Derso, 2015). Theileria are obligate intracellular protozoan parasites that infect both wild and domestic Bovidae throughout much of the world (some species also infect small ruminants). They are transmitted by ixodid ticks, and have complex life cycles in both vertebrate and invertebrate hosts (OIE, 2014). There are a number of species of Theileria spp. that infect cattle; the two most pathogenic and economically important are T. parva and T. annulta (OIE, 2014). So globally the most common cause of bovine theileriosis is Theileria annulata and Theileria parva (Kohli et al., 2014; Gul et al., 2015; Bhatnagar et al., 2015; Gebrekidan et al., 2016). T. annulata infection (Tropical theileriosis) is characterized by high fever, weakness, weight loss, inappropriate appetite, conjunctival petechia, enlarged lymph nodes, and anemia. Lateral recumbency, diarrhea and dysentery are also associated with later stages of infection (Radostits et al., 2007 and Muhanguzi et al., 2014). Cattle may also develop an extremely fatal condition referred to as turning sickness. In this disease, capillaries of central nervous system are blocked by infected cells and leads to neurologic symptoms (Gul et al., 2015).

The incubation period varies from 4 to 14 days after attachment of the infected ticks to the host. The disease may last as little as three to four days in the acute form or may be prolonged for about 20 days (Bakor, 2008). Mahmmod et al., (2011) reported different degrees of the characteristic clinical signs of tropical theileriosis like fever $\left(>103^{\circ} \mathrm{F}\right)$, enlargement of the superficial lymph nodes (acute form), anorexia, pale or congestion of the visible mucous membranes, conjunctivitis, severe congestion of the eyes, excessive lacrimation, corneal opacity, respiratory signs from serous nasal discharge to cough, purulent nasal discharge, and dyspnoea (chronic form). Unlike T. parva, which causes only a small reduction in circulating erythrocytes, mild to moderate anaemia is observed in tropical theileriosis, although pathology produced by the schizont stage is usually the primary cause of mortality (Morrison, 2015).The present study documents bovine theileriosis in young crossbred Sahiwal calf aged above one month and its effective therapeutic management.

\section{History and Observations}

Calf aged above one month was presented at Teaching Veterinary Clinical Complex IIVER Rothak Haryana with a history of high body temperature $\left(106.7^{\circ} \mathrm{F}\right)$, anorexia, bilateral pre scapular lymphadenitis and tick infestation (Figure 1), dullness, staggering gait, absence of suckling reflex with slight pale mucus membrane. The calf was suspected to heamoprotozoan diseases and for confirmation, five blood smears were made from ear tip for presence of any piroplasms in red blood cells. Pre-scapular lymph node aspiration was also performed for the presence of Koch's blue bodies, indicative of piroplasm infection. The blood and lymph node smears were prepared and stained with Giemsa stain and examined under microscope $100 \mathrm{X}$ magnification for the presence of any intra-erythrocytic piroplasms and Koch's blue bodies.

\section{Therapeutic Management and Discussion}

The calf was diagnosed positive for theileria after blood smear and pre-scapular lymph node smear examination stained with Giemsa stain. Intra-erythrocytic piroplasm and Koch's blue bodies were found (Figure 2) on microscopic examination (100X) of prepared smears, similarly Gupta et al., (2004) reported theileriosis in 7 day old bovine calf. According to Mudgal (1993), Sharma and Nichani (1990) and Grewal (1992, young calves are highly susceptible for theileriosis hence the calves should be given proper immuno-prophylactic measures immediately after birth. 
Fig.1 A male calf showing enlarged pre-scapular lymph nodes (A) with ectoparasites/tick manifestation $(\mathrm{B})$ in the axillary region
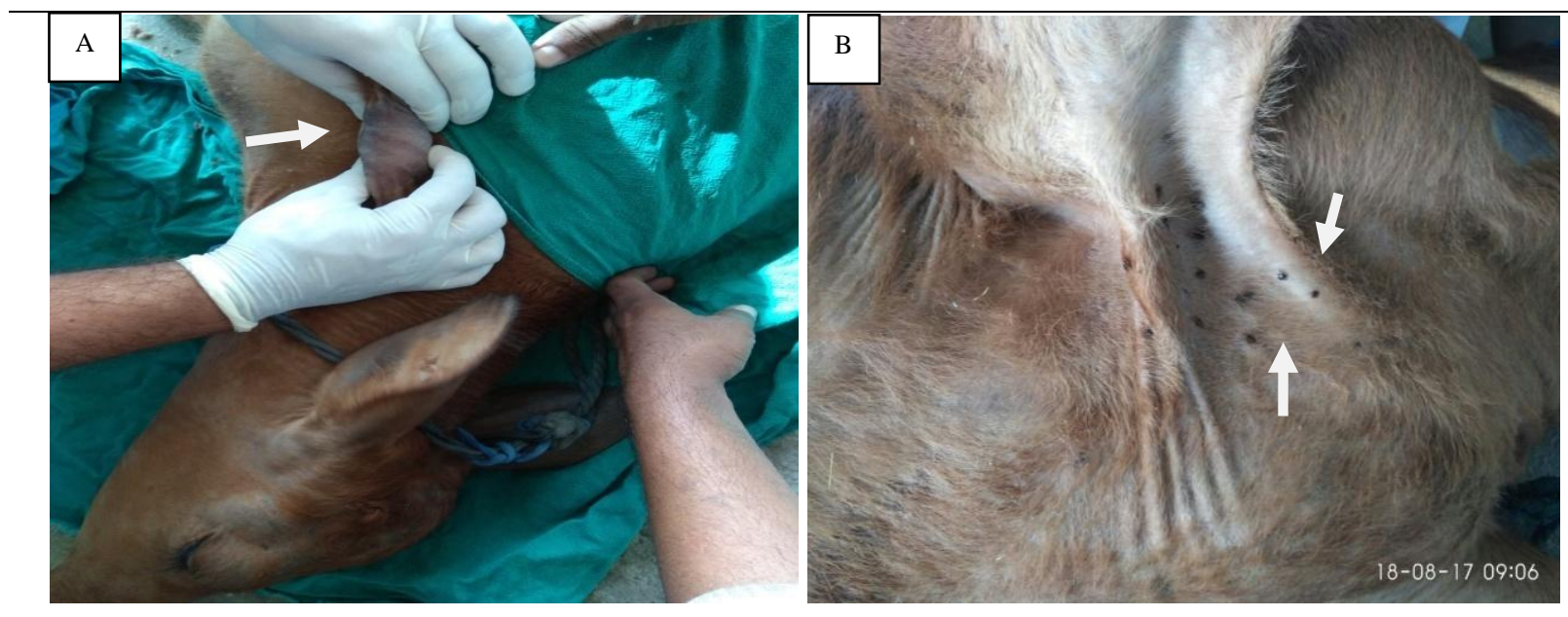

Fig.2 Pre-scapular lymph node smear shows Koch's blue bodies infected lymphocytes (A) and blood smear showing Intra-erythrocytic piroplasms (Theileria) (B) (Giemsa, 100X)

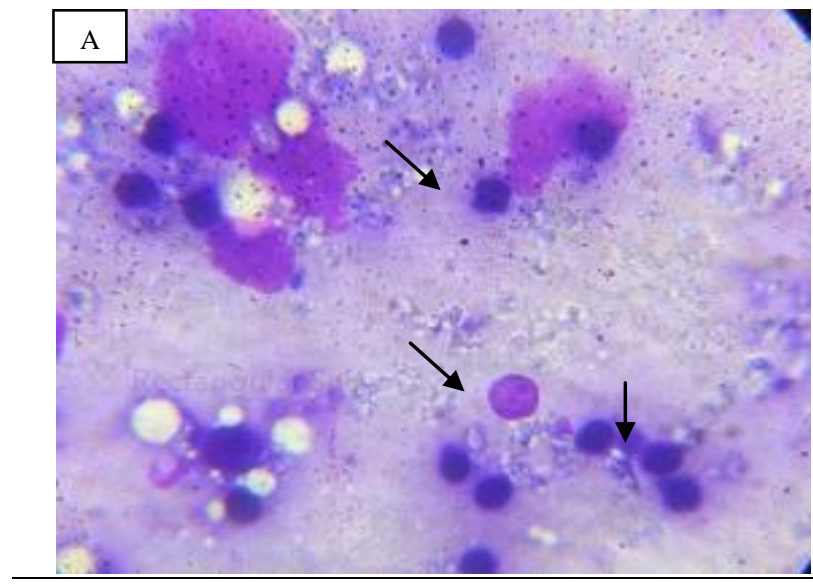

In the present study the calf was treated with Buparvoquone (Butalex) at the dose rate of $2.5 \mathrm{mg} / \mathrm{kg} \mathrm{BW}$ injected deep intramuscular in the neck region along with Normal saline 150 ml IV, Melonex $1 \mathrm{~mL}$ IM, Avil $1.5 \mathrm{~mL}$ IM, Tribivet $2 \mathrm{~mL}$ IM. The calf recovered with single dose of buparvaquone.

This is in accordance with Gupta et al., (2004) and Naik et al., (2010) who used Buparvoquone along with supportive therapy for the successful treatment. Theileriosis is one of the most important arthropod-borne

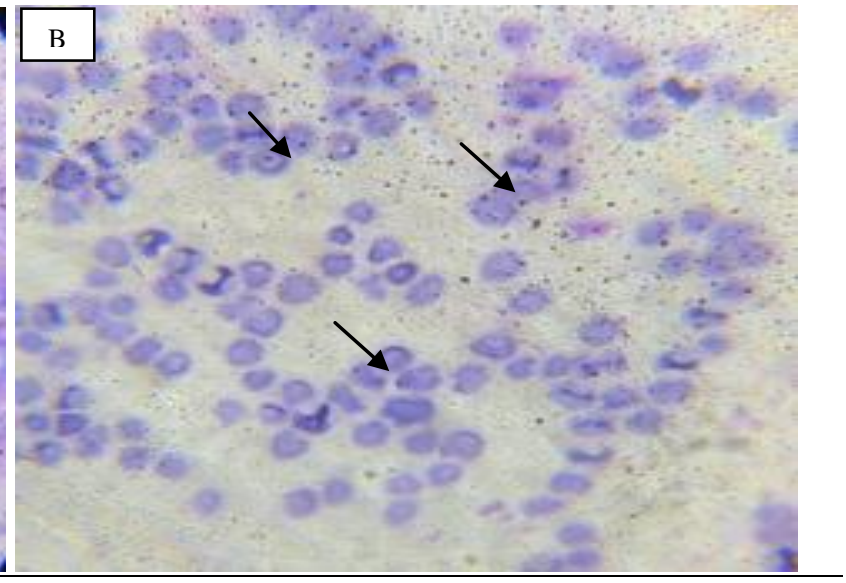

blood protozoan diseases, leading to morbidity and mortality especially in calves, which are commonly affected during the perinatal period. The blood and lymph node smears are used as supplementary methods for the laboratory diagnosis of the presence of any intra-erythrocytic piroplasms and koch's blue bodies respectively. In the present case, it was found that a single dose of buparvaquone is effective against cases of theileriosis along with supportive therapy when treated at the earliest. 


\section{References}

Bhatnagar, C. S., Bhardawaj, B., Sharma, D. K., and Meena, S. K. 2015. Incidence of Haemoprotozoan diseases in Cattle in Southern Rajasthan, India. International Journal of Current Microbiology and Applied Science, 4(3), 509-514.

Demessie, Y., and Derso, S. 2015. Tick Borne Hemoparasitic Diseases of Ruminants: A Review. Advance in Biological Research, 9(4), 210-224.

Gebrekidan, H., Gasser, R. B., Baneth, G., Yasur-Landau, D., Nachum-Biala, Y., Hailu, A., and Jabbar, A. 2016. Molecular characterization of Theileria orientalis from cattle in Ethiopia. Ticks and Tick-borne Dis.

Grewal, A. S., 1992. Development of theilaria vaccine for control of bovine tropical theileriosis. Proceeding of Annual Scientist Meet of All India Co-ordinated Research Projects on 'Intracellular blood protista with special reference to the immunoprophylaxis and control', 8thFebruary, Haryan Agricultrual University, Hisar, India.

Gul, N., Ayaz, S., Gul, I., Adnan, M., Shams, S., and ul Akbar, N. 2015. Tropical Theileriosis and East Coast Fever in Cattle: Present, Past and Future Perspective. International Journal of Current Microbiology and Applied Science, 4(8), 1000-1018.

Gupta, S. K., Anish Yadav, Raina, A. K. and Rajiv Singh 2004. Theileriosis in a seven-day old bovine calf - a case report. Indain J.Vet.Med.24, 55.

Kasozi, K. I., Matovu, E., Tayebwa, D. S., Natuhwera, J., Mugezi, I., and Mahero, M. 2014. Epidemiology of increasing hemo-parasite burden in Ugandan Cattle. Open Journal. of Veterinary Medicine, 4(10), 220.

Kohli, S., Atheya, U.K., Thapliyal, A. 2014. Prevalence of theileriosis in cross- bred cattle: its detection through blood smear examination and polymerase chain reaction in Dehradun district, Uttarakhand, India. Veterinary World, 7(3): 168-171.

Mahmmod, Y. S., Elbalkemy, F. A., Klaas, I. C., Elmekkawy, M. F., and Monazie, A. M. 2011. Clinical and haematological study on water buffaloes (Bubalus bubalis) and crossbred cattle naturally infected with Theileria annulata in Sharkia province, Egypt. Ticks and tick borne diseases, 2(3), 168-171.

Mans, B. J., Pienaar, R., and Latif, A. A. 2015. A review of Theileria diagnostics and epidemiology. International Journal for Parasitology: Parasites and Wildlife, 4(1), 104- 118.

Morrison, W. I. 2015. The aetiology, pathogenesis and control of theileriosis in domestic animals. Revue scientifique et technique (International Office of Epizootics), 34(2), 599- 611.

Mudgal, V.K., 1993. Studies on crossimmunity and field trials with cell culture vaccine against bovine tropical theileriosis. Post Graduate Thesis. Haryana. Agricultural University, Hisar, India.

Naik, G., Ananda, J. and Kavitha, R.B. 2010. Theileriosis in calves and its successful treatment. Vet. World 3:4.

Radostits, O.M., Gay, C.C., Hinchcliff, K.W., Constable, P.D. 2007. Veterinary medicine: A textbook of the diseases of cattle, horses, sheep, pigs and goats, 10th edn. Elsevier, Philadelphia. Pp. 1522- 1532

Sharma, R.D., and Gautam, O.P. 1977. Theileriasis in cattle. Indian J. Parasitol. 1: 87-91.

Sharma, R.D., and Nichani, A.K. 1990. A cell culture vaccine against bovine tropical theileriosis for young calves. Proceeding of First Asian Congress of Veterinary Parasitology, 6-8th October, 
Bihar Veterinary College, Patna, India. Sitotaw, T., Regassa, F., Zeru, F., and Kahsay, A. G. 2014. Epidemiological significance of major hemoparasites of ruminants in and around Debre-Zeit, Central Ethiopia. Journal of
Parasitology and Vector Biology, 6(2), 16-22.

Spickler, A. R., 2010. Emerging and exotic diseases of animals, 4th edn, CFSPH Iowa State University, lowa USA pp. 283-285.

\section{How to cite this article:}

Sheikh Tajamul Islam, Rouf Rashid Dar, Amir Amin Sheikh, Pooja Dogra, Rohini Gupta, Priti Patel, Mohd Younis Ganaie and Jaan Mohammad Wani. 2017. Theileriosis in a Calf: A Case Study. Int.J.Curr.Microbiol.App.Sci. 6(10): 1400-1404.

doi: https://doi.org/10.20546/ijcmas.2017.610.165 